\title{
MAARSY - the new MST radar on Andøya: first results of spaced antenna and Doppler measurements of atmospheric winds in the troposphere and mesosphere using a partial array
}

\author{
G. Stober ${ }^{1}$, R. Latteck ${ }^{1}$, M. Rapp ${ }^{1}$, W. Singer ${ }^{1}$, and M. Zecha ${ }^{1}$ \\ ${ }^{1}$ Leibniz-Institute of Atmospheric Physics at the Rostock University, Schlossstr. 6, 18225 Kühlungsborn, Germany \\ Correspondence to: G. Stober (stober@iap-kborn.de)
}

\begin{abstract}
MST radars have been used to study the troposphere, stratosphere and mesosphere over decades. These radars have proven to be a valuable tool to investigate atmospheric dynamics. MAARSY, the new MST radar at the island of Andøya uses a phased array antenna and is able to perform spaced antenna and Doppler measurements at the same time with high temporal and spatial resolution. Here we present first wind observations using the initial expansion stage during summer 2010. The tropospheric spaced antenna and Doppler beam swinging experiments are compared to radiosonde measurements, which were launched at the nearby Andøya Rocket Range (ARR). The mesospheric wind observations are evaluated versus common volume meteor radar wind measurements. The beam steering capabilities of MAARSY are demonstrated by performing systematic scans of polar mesospheric summer echoes (PMSE) using 25 and 91 beam directions. These wind observations permit to evaluate the new radar against independent measurements from radiosondes and meteor radar measurements to demonstrate its capabilities to provide reliable wind data from the troposphere up to the mesosphere.
\end{abstract}

\section{Introduction}

Over the past decades mesosphere-stratosphere-troposphere (MST) radars have proven to be a powerful technique for the investigation of atmospheric dynamics from the troposphere up to the mesosphere (e.g. Hocking, 2011). On the island of Andøya first radar measurements with the mobile SOUSY radar were carried out on a campaign basis since 1983 (Czechowsky et al., 1988; Reid et al., 1988). The Middle Atmosphere Alomar Radar System (MAARSY) is a new scientific instrument on the island of Andøya and provides continued observations of tropospheric and mesospheric winds, which started with the Alomar-SOUSY radar in 1994-1997 (Singer et al., 1995) and the ALWIN radar from 1998-2009 (Latteck et al., 1999). In particular, the investigation of the polar mesosphere is a key objective of MAARSY. The system is designed to provide temporally and spatially highly resolved measurements of atmospheric winds and its variation by waves and turbulence.

The main focus of MAARSY is the investigation of small scale gravity waves and the underlying scattering processes at mesospheric altitudes. The polar mesosphere shows two characteristic radar signatures such as polar mesospheric summer and winter echoes (PMSE/PMWE) (e.g. Rapp and Lübken, 2004; Kirkwood, 2007). Besides being interesting phenomena in their own right, these radar returns provide an ideal tracer to gain information about the dynamics of the background atmosphere. MAARSY promises new insights into these phenomena due to its flexible beam steering capabilities and its higher power compared to the previous VHF radars operated at polar latitudes. Since May 2010 MAARSY has been in operation using an initial expansion stage (Latteck et al., 2010, 2012a,b). During summer 2010 first experiments were conducted to test the system's beam steering capabilities and to evaluate the wind measurements with radiosondes and co-located meteor radar observations.

Beside the mesospheric observations, the radar is also a helpful tool to study the polar troposphere and lower stratosphere and due to its location at the edge of the Scandinavian mountains it is possible to investigate the generation of mountain waves. However, before the radar can be used to investigate these phenomena the system has to be evaluated to ensure the quality of the wind observations. 
Table 1. Experimental radar configurations for the presented data.

\begin{tabular}{lrrr}
\hline Experiment & meso & tropo1 & tropo2 \\
\hline PRF & $1250 \mathrm{~Hz}$ & $5000 \mathrm{~Hz}$ & $5000 \mathrm{~Hz}$ \\
coherent integrations & 2 & 128 & 16 \\
Pulse code & 8 bit coco & mono & 4 bit coco \\
number of Beams & 25 & 1 & 8 \\
duty cycle & $2 \%$ & $1 \%$ & $4 \%$ \\
data points & 1024 & 1024 & 1024 \\
range resolution & $300 \mathrm{~m}$ & $300 \mathrm{~m}$ & $300 \mathrm{~m}$ \\
pulse length & $2 \mu \mathrm{s}$ & $2 \mu \mathrm{s}$ & $2 \mu \mathrm{s}$ \\
\hline
\end{tabular}

In this paper we focus on the analysis of prevailing winds using the spaced antenna (SA) (e.g. Röttger and Vincent, 1978; Röttger, 1981; Vincent and Röttger, 1980; Larsen and Röttger, 1982; Briggs, 1984; Holdsworth and Reid, 1997; Holdsworth, 1999) and the Doppler beam swinging (DBS) method (e.g. Woodman and Guillen, 1974; Briggs, 1980; Baelen et al., 1990; May, 1990) at tropospheric and mesospheric altitudes. In particular, MAARSY has the ability to perform wind measurements combining both techniques due to its multi-channel receiver system. This permits to analyze data from the same experiment with both techniques and to investigate eventual biases between the techniques. Such investigations were already performed with the SOUSY Radar (e.g. Röttger and Czechowsky, 1980; Röttger, 1983), but the new MAARSY permits to analyze differences between these techniques with a significantly increased temporal resolution by using the same data for the SA and DBS vector winds.

\section{Experimental setup}

MAARSY is a phased array operating at a frequency of $53.5 \mathrm{MHz}$. The array consists of 433 antennas each connected to its own transceiver module of $2 \mathrm{~kW}$. The array is sub-structured in groups of 7 antennas called hexagons and groups of 49 antennas called anemones. The color code in Fig. 1 represents the initial expansion stage of the array. Each colored area marks a group of 49 antennas or one anemone. The smaller hexagon structure of 7 antennas is also visible. The term hexagon refers to the underlying geometric shape formed by the 7 antenna sub-array. More details are given in Latteck et al. (2010, 2012a,b).

The first experiments were conducted in summer 2010 and only used a partial array, consisting of 3 adjacent anemones and some additional hexagons (Latteck et al., 2010, 2012b). This expansion stage resulted in a transmitting power of approximately $294 \mathrm{~kW}$ and a beam width of $6^{\circ}$. This preliminary operational array had already its full beam steering capabilities for all off-zenith angles $<30^{\circ}$ and utilized a 16 channel receiver system. The radiation pattern for the vertical and for off-zenith pointed beam directions are given in Latteck et al. (2010, 2012b). As shown there the radar

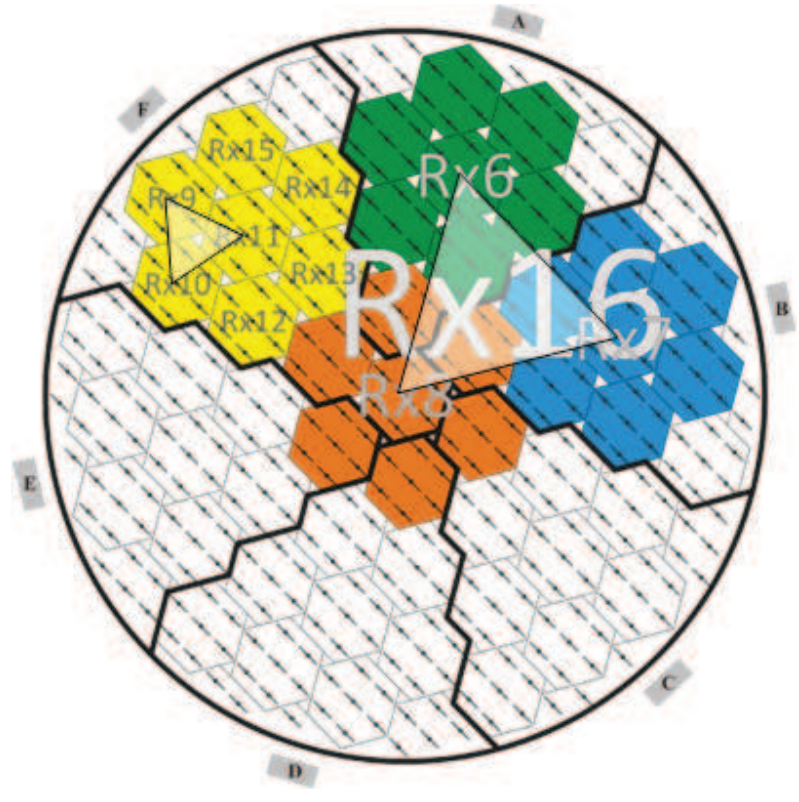

Fig. 1. Configuration of receiving channels for the experiment during summer 2010.

does not generate severe side or grading lobes for this offzenith angular range. The radar parameters for the different experiments in the troposphere and mesosphere including PRF, range resolution, pulse coding, coherent integrations and pulse length are summarized in Table 1 .

The configuration of the receiver channels is given in Fig. 1. One channel was used to sample the complete available array and 6 other channels were reserved for spaced antenna experiments. A full correlation analysis (FCA) of the spaced antenna experiment requires different baseline length in dependence of the correlation times one expects at the analyzed altitude. Therefore, a larger triangle is necessary to measure tropospheric winds and a smaller triangle is used for a mesospheric analysis, due to the much shorter autoand cross-correlation times.

In this paper we present results from one tropospheric and two mesospheric experiments. The tropospheric experiment contained two sequences with different experiment parameters (see Table 1). One sequence contained 8 oblique beams at two different zenith angles $\left(5^{\circ}\right.$ and $\left.10^{\circ}\right)$ and one sequence was used for a vertical beam only. The beam positions for the tropospheric experiment are shown in Fig. 2a with regard to the coastline of the island Andøya. The red circles indicate the beam width at an altitude of $10 \mathrm{~km}$ where it obtains a value of $1 \mathrm{~km}$ in diameter. The experiment was designed to compare simultaneous FCA spaced antenna winds and classical DBS derived winds using the multi-channel recording system of MAARSY.

The mesospheric observations consisted of a systematic scanning experiment of PMSE with the objective to observe the 3-D structure of the distribution of scatterers in such a 
target. The first experiment consists of 25 beams at four different zenith angles $\left(0^{\circ}, 5^{\circ}, 10^{\circ}\right.$ and $\left.15^{\circ}\right)$. The beam positions are shown in Fig. 2. The red circle indicates the beam width at an altitude of $84 \mathrm{~km}$, which is a typical altitude for the occurrence of PMSE. The experiment is subdivided into 4 sequences containing 7 beams each (Latteck et al., 2012a). Every experiment contains 6 oblique and a vertical beam, which results in a slightly better temporal resolution of the spaced antenna winds computed from the time series of the vertical beam than the DBS-winds. However, for the comparisons presented here the SA winds are interpolated to the same temporal resolution as the all sky fit (DBS) wind measurements.

The second mesospheric experiment sequence included 91 positions with 6 different zenith angles $\left(0^{\circ}, 5^{\circ}, 10^{\circ}, 15^{\circ}, 20^{\circ}\right.$ and $25^{\circ}$ ). Figure $2 \mathrm{c}$ ) indicates again the beam positions at an altitude of $84 \mathrm{~km}$.

\section{Radar wind observations}

The multi-channel recording system of MAARSY allows to derive prevailing atmospheric winds by two different techniques. In the following we briefly summarize the basic differences among these techniques and provide a short overview of both methods.

The spaced antenna method relates to radars with multiple, but at least three, spatially separated receiving antennas, which each have to be connected to its own receiver. To derive horizontal winds from spaced antenna measurements several analysis methods have been developed, e.g. similar fades (Mitra, 1949), the spatial correlation analysis (SCA) (Briggs, 1968) or the full correlation analysis (FCA) (e.g. Briggs et al., 1950; Briggs, 1984; Phillips and Spencer, 1955; Fedor, 1967; Gregory et al., 1979). The MAARSY spaced antenna winds are determined by using the FCA method. The basic idea of such an analysis is given by the assumption that the motion of an anisometric diffraction pattern over the radar site is mainly governed by atmospheric winds. In contrast to other correlation methods, the FCA takes into account that spatial (cross correlation) and temporal (autocorrelation) variations of the diffraction pattern likely occur. However, the FCA method still assumes that these variations can be described by the same functional form (Baelen et al., 1990). A detailed investigation of the instrumental effects and biases of the FCA is given in Hocking et al. (1989); Holdsworth and Reid (1997); Holdsworth (1999).

The second commonly used method to derive atmospheric winds are Doppler beam swinging experiments, which require a narrow and steerable beam, but only one receiver channel. Such radars operate often as monostatic systems and use the complete array for transmission and reception. The transmitted electromagnetic wave is backscattered from variations of the refractive index. Below $100 \mathrm{~km}$ these variations are mainly caused by turbulence or atmospheric in- a)

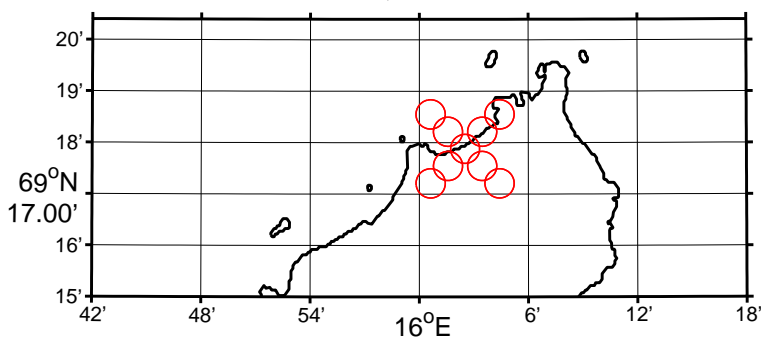

b)

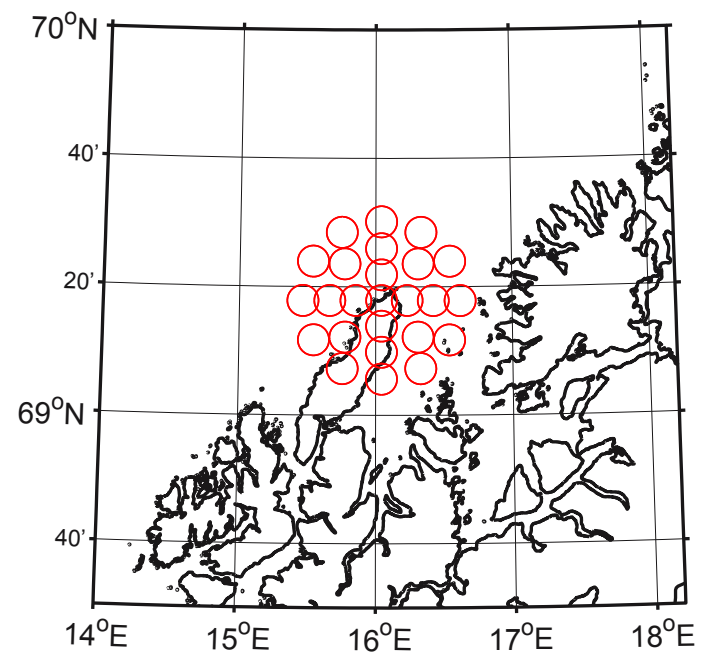

c)

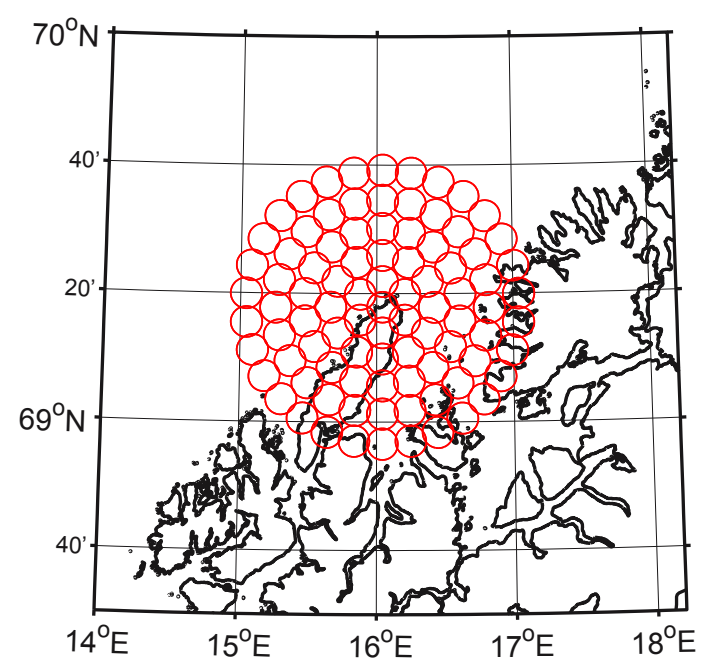

Fig. 2. (a) shows the beam positions at $10 \mathrm{~km}$ altitude for the tropospheric experiment. (b) and (c) show the beam positions for the sequential 25 and 91 beam experiments at an altitude of $84 \mathrm{~km}$.

homogeneities traveling with a mean wind speed. Hence, the backscattered wave is Doppler shifted due to these atmospheric winds and can easily be converted into a line of sight velocity (radial velocity). Measuring the line of sight velocity in at least two different directions, which are 
ideally perpendicular to each other allows to derive a mean horizontal wind speed by solving Eq. (1).

$v(\theta, \phi)_{\mathrm{rad}}=u \cos \phi \sin \theta+v \sin \phi \sin \theta+w \cos \theta$,

where $u, v$ and $w$ are the zonal, meridional and vertical wind speed. The angles theta and phi correspond to the zenith distance and azimuth angles with reference to east (mathematical convention). A more general form is called "all sky fit" and is often used to derive meteor radar winds (Hocking and Thayaparan, 1997; Hocking et al., 2001). The all sky fit minimizes the quantity under the assumption of a vanishing vertical mean wind $(w=0)$;

$\Lambda=\sum_{i=1}^{N}\left(v_{\mathrm{rad}_{i}}-u \cos \left(\phi_{i}\right) \sin \left(\theta_{i}\right)-v \sin \left(\phi_{i}\right) \sin \left(\theta_{i}\right)\right)^{2}$

in a least squares sense and is ideally applied to derive a mean horizontal wind if a larger number of beam directions is available. The index $i$ in Eq. (2) labels the number of the meteor or beam pointing direction. Hence, this generalized DBS seems to be suitable to determine prevailing winds from the multi-beam scanning experiments conducted with MAARSY. However, for large zenith angles $\left(>25^{\circ}\right)$ both DBS methods should only be used to derive a mean horizontal wind speed. Specular meteor radars often observe the majority of the echoes at zenith angles between $35-70^{\circ}$ offzenith. The huge horizontal extent of the measurement volume can exceed $500 \mathrm{~km}$ in diameter at $90 \mathrm{~km}$ altitude. For such large observation areas Hocking et al. (2001) suggested rather to assume $w=0$ than to estimate a mean vertical velocity. In the mesosphere the horizontal wind speed can exceed the vertical velocity by up to 2 orders of magnitude, which leads for large off-zenith angles to an almost negligible contribution to the line of sight velocity. Small errors in the line of sight velocity translate into large errors in the vertical velocity. Estimating the vertical wind form such observations often tends to produce unrealistic values.

\section{First results of tropospheric wind measurements}

The first tropospheric observation campaign with MAARSY started the 4 August 2010. This tropospheric experiment focused on the evaluation of the new radar against wind observations with radiosondes launched at the nearby Andøya Rocket Range. This experiment contained 9 beam positions in the DBS sequence consisting of 8 oblique beams at two different zenith angles of $5^{\circ}$ and $10^{\circ}$ (see Table 1 , tropo2) and one sequence containing the vertical beam (see Table 1, tropo1). The much higher number of coherent integrations for the vertical beam improved the signal-tonoise-ratio to perform a reliable spaced antenna wind analysis reaching a comparable altitude than for the Doppler observation. The temporal resolution of both sequences was approximately $2 \mathrm{~min}$.

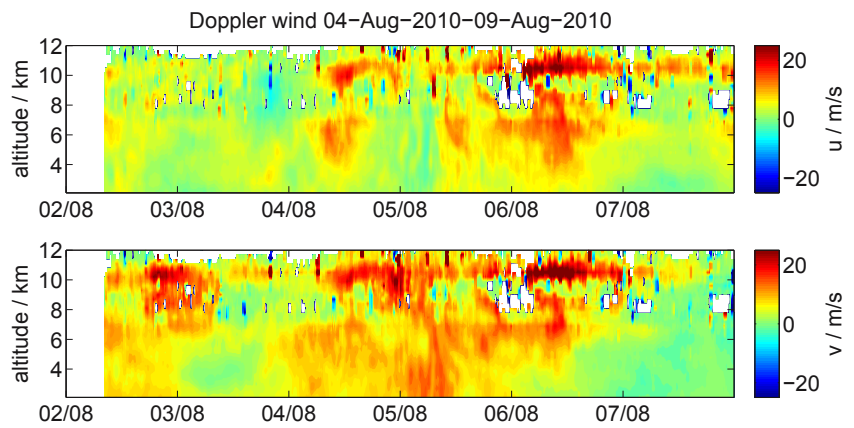

Fig. 3. Tropospheric wind situation at the beginning of August derived from a MAARSY Doppler experiment.

The tropospheric wind situation at the beginning of $\mathrm{Au}-$ gust 2010 is shown in Fig. 3. During this time the weather at Andenes was driven by several low-pressure systems over the Northern Atlantic and Northern Scandinavia. These low-pressure areas generated a prevailing wind from South/Southwest, which remained almost stable during the complete campaign period. The prevailing winds shown in Fig. 3 were computed using 15 min averages.

The first comparison focuses on the evaluation of the spaced antenna winds and the Doppler measurements. In Fig. 4 the FCA and DBS winds are compared using the complete campaign data and all available height gates. The correlation coefficients for the zonal wind $(r=0.90)$ and meridional wind $(r=0.92)$ confirm a reasonably good agreement with almost no systematic bias. However, the scattering in Fig. 4 around the red slope 1 line points out that there are some differences between the DBS and FCA winds, which are only partly explainable by the different observation volumes. There are systematic errors related to the FCA winds (Holdsworth and Reid, 1997) and the DBS determined winds. In particular, the DBS technique requires an accurate determination of the effective beam pointing direction, which can be altered by aspect sensitive scattering processes and the distribution of scatterers in the radar volume (Hocking et al., 1990; Worthington et al., 1999; Worthington, 1999; Worthington et al., 2000). However, Röttger and Czechowsky (1980) demonstrated that already at $7^{\circ}$ off-zenith angle the aspect sensitivity shows a reduced impact. The tropospheric experiment used in this study uses up to $10^{\circ}$ off-zenith angle, which should further decrease the impact of aspect sensitivity on the computed vector winds. In fact, the presented comparison is not sufficient to give a final answer on this question.

In parallel to the radar observations in the troposphere insitu wind measurements were conducted. A radiosonde campaign at the Andøya Rocket Range from 2 August- 8 August 2010 provided an excellent opportunity for a detailed comparison of radiosonde and radar horizontal winds. During the campaign 18 radiosondes were launched. The trajectories (blue) as well as the MAARSY beam positions at $10 \mathrm{~km}$ altitude (red) are shown in Fig. 5. 

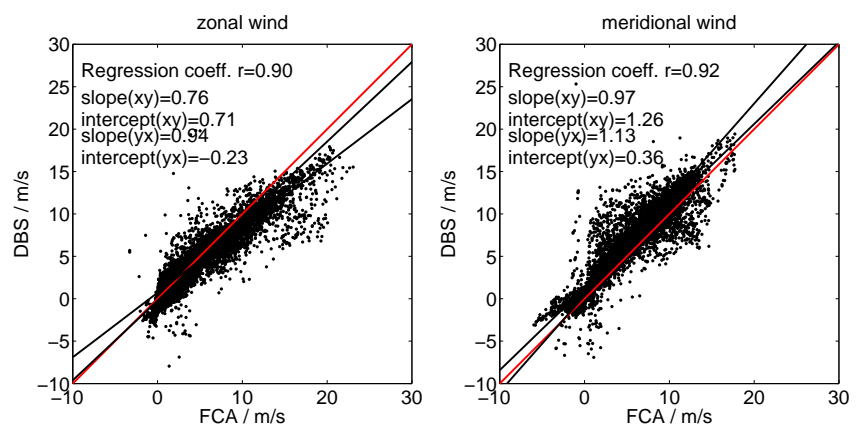

Fig. 4. Comparison of DBS and FCA zonal and meridional winds in the troposphere in the altitude range between $1.8-8 \mathrm{~km}$.

The general problem in comparing radiosondes and radar measurements is the rapid motion of the balloon out of the observation volume of the radar. To avoid any bias in the comparison due to the rapidly increasing horizontal distance we defined spatial and temporal coincidence criterion. The spatial coincidence criteria is given by the green circle, which labels a horizontal distance of $8 \mathrm{~km}$ around the radar. For this area we assume that the balloon observes the same horizontal wind as the radar. As temporal coincidence we considered the time span where the radiosonde reached an altitude of $1.8 \mathrm{~km}$ (corresponding to the lowest radar range gate) and the time where the horizontal distance of the balloon exceeded $8 \mathrm{~km}$. In addition, the radiosonde measurements were interpolated to the altitude resolution given by the radar. We computed an average wind for each $300 \mathrm{~m}$ altitude gate centered at the corresponding altitude gate of the radar.

In Fig. 6 the scatter plots of DBS wind versa the radiosonde observations are shown. The correlation coefficients are calculated for the wind speed $(r=0.85)$ and the wind direction $(r=0.83)$. In particular, the wind direction of both observations are in reasonable agreement, which is pointed out by the slopes for both fits being close to 1 and an intercept smaller than $1 \mathrm{~m} \mathrm{~s}^{-1}$. The black line indicate the slopes of both fits (changing xy-axis) to obtain an estimate of a possible bias. Further, it is surprising that the wind speed shows this good agreement, because we did not apply an aspect sensitivity correction. At least during this campaign the effective and nominal beam directions seemed to be in coincidence and were not significantly altered due to aspect sensitive backscatter.

The FCA determined wind speed shows a smaller correlation for the wind speed of $r=0.84$ and $r=0.84$ for the wind direction. Also the general agreement provides some evidence that the FCA winds tend to underestimate the radiosonde winds, which is in agreement with the study of Reid et al. (2005). In this work a data base of 3000 radiosonde ascents was used to determine the bias of the FCA winds to be in the order of $7 \%$ for the altitude range between 2$6 \mathrm{~km}$. However, the available data from the 18 radiosondes are not sufficient to analyze this in detail. The bias in the

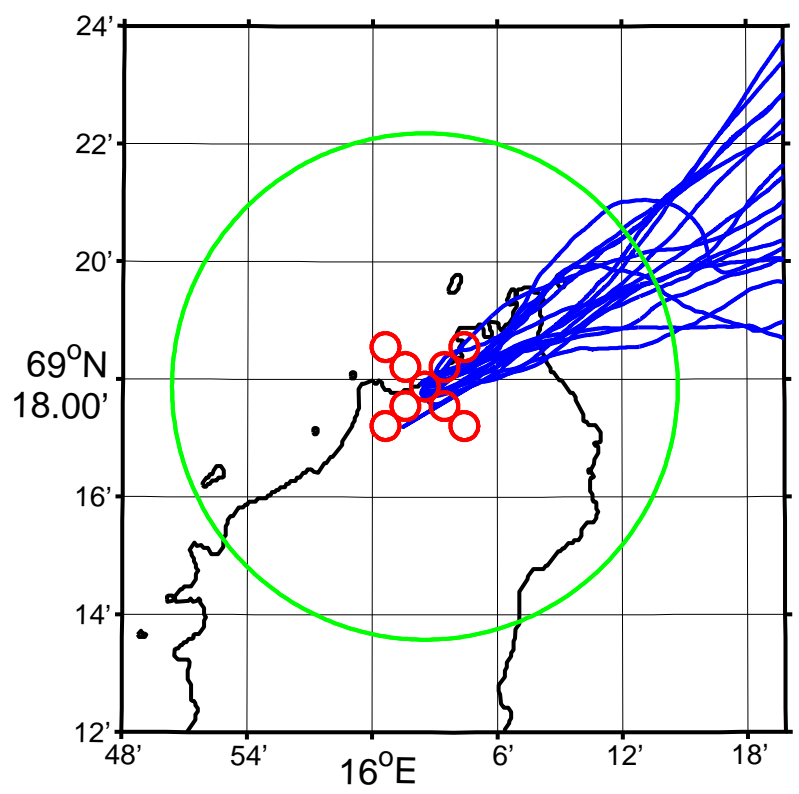

Fig. 5. Lambert projection of island of Andøya in Northern Norway. The position of the tropospheric beams at an altitude of $10 \mathrm{~km}$ is labeled by red circles. The blue lines are the trajectories of the radiosondes launched at the ARR.

wind direction is slightly larger compared to the DBS winds, but shows the same tendency.

\section{First results of mesospheric winds during PMSE}

Polar mesospheric summer echoes are a well-known radar tracer at Arctic and Antarctic latitudes. The backscatter from these echo structures permits to measure horizontal and vertical winds with high spatial and temporal resolution (e.g. Zecha et al., 2001; Rapp et al., 2011) at mesospheric altitudes. Over the past decades the investigation of the scattering processes and the dynamics within the PMSE have become an important field of research (see Rapp and Lübken, 2004, for a review).

The persistence and strength of these echoes provide a chance to gain information about an atmospheric region, which is otherwise rarely accessible by VHF radars due to a lack of scatterers. In particular, the height of occurrence of PMSE between $80-90 \mathrm{~km}$ altitude permits to investigate the atmospheric dynamics with a significantly improved temporal and spatial resolution compared to meteor radars and MF radars which are widely used in this height range.

Close to the MAARSY facility there is also a co-located meteor radar (MR). The Andenes MR operates at $32.55 \mathrm{MHz}$ with a transmitting power of $20 \mathrm{~kW}$. The receiving antennas are crossed Dipoles ensuring an almost perfect azimuthal radiation pattern. The system records between 8000 to 20000 meteors per day. The typical observed volume used for the wind determination has a diameter of $500 \mathrm{~km}$ at 

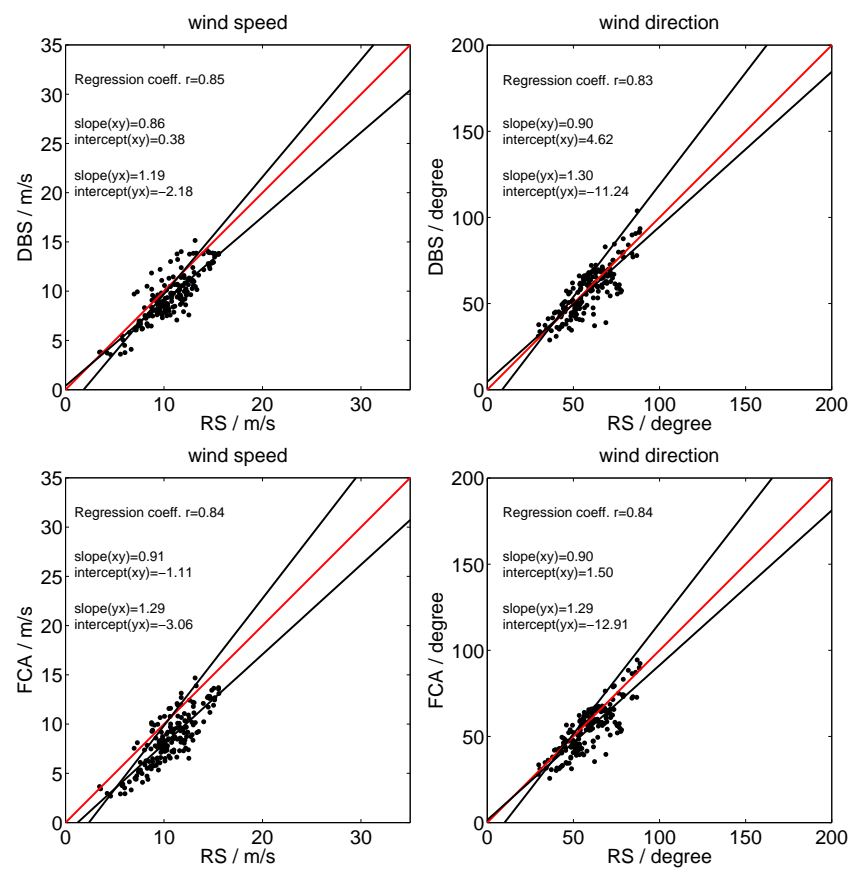

Fig. 6. Comparison of DBS and FCA prevailing winds with the horizontal wind measured by the radiosondes.

$90 \mathrm{~km}$ altitude. A more detailed description of the meteor radar wind measurements and wave activities can be found in Stober et al. (2012).

At the end of July 2010 MAARSY recorded a rather strong PMSE employing a 25 beam scanning experiment. In Fig. 7 we compared the MAARSY and MR horizontal winds. The contour of the PMSE is given by the black line. Inside the contour line the wind is computed from the radial velocities measured by MAARSY using a Doppler analysis similar to those of the MR with a temporal resolution of $15 \mathrm{~min}$. Outside the contour line the MR winds are shown. These winds were derived by using a running window of $1 \mathrm{~h}$, which was shifted in steps of 15 min and centered at the reference time of the corresponding MAARSY wind analysis to get a similar temporal resolution than MAARSY. The color code in Fig. 7 visualizes a strong diurnal and semidiurnal tidal activity, which is considered to cause the minimum in the PMSE occurrence in the afternoon (e.g. Hoffmann et al., 1997, 1999; Barabash et al., 1998; Klostermeyer, 1999; Li and Rapp, 2011). However, taking further into account the MR winds the phase lines of the upward propagating tidal structure becomes even more obvious.

The reasonable agreement visualized in the contour plot is also confirmed by correlating the zonal and meridional wind of both radar measurements, which is shown in Fig. 8. The correlation coefficients for the zonal and meridional wind are $r=0.78$ and $r=0.79$, respectively. The intercepts of the fits indicate a reasonable good agreement. However, the slopes reveal some larger discrepancies between both radars, which
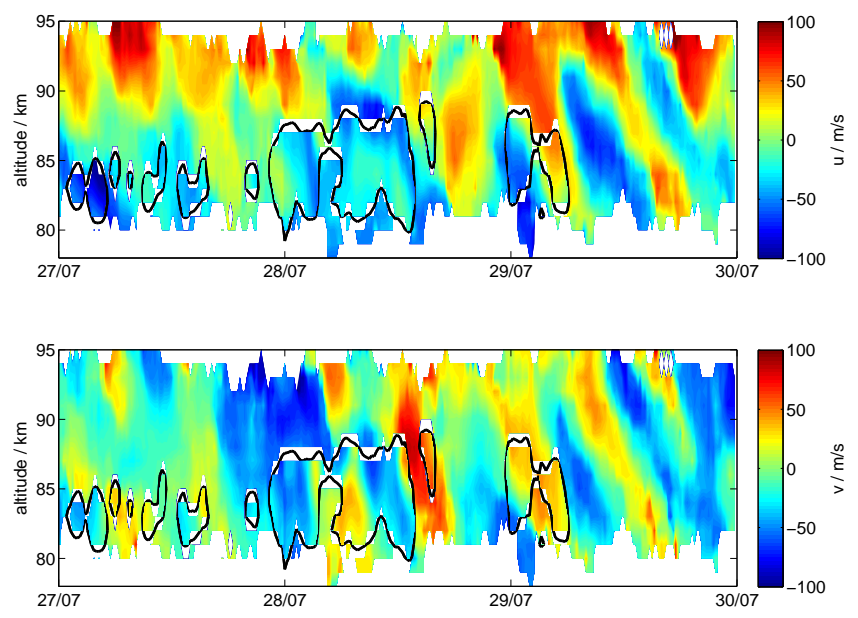

Fig. 7. Comparison of the prevailing zonal and meridional wind measured with the Andenes Meteor Radar. The black line represents a contour line of an existing PMSE. The wind field within the contour line is determined from a 25 beams MAARSY scanning experiment.

is explainable considering the spatial and temporal resolutions of both radars: MAARSY sampled at a range resolution of $300 \mathrm{~m}$ in the scanning experiment and the wind is computed on the basis of such $300 \mathrm{~m}$ height gates as well. In contrast, the MR wind measurement is interpolated to the same vertical resolution by using $3 \mathrm{~km}$ altitude bins shifted by $300 \mathrm{~m}$ centered at the same height as the appropriate MAARSY altitude gate.

In addition the observation volumes differ considerably. The meteor radar records meteors in a cone with almost $500 \mathrm{~km}$ diameter at PMSE altitudes, in contrast to the $80 \mathrm{~km}$ diameter of the PMSE scanning experiment. In principle it is possible to limit the observation volume of the MR to the same size as MAARSY considering only meteors with offzenith angles smaller than or equal to the beam positions shown in Fig. 2. But such a small volume would dramatically decrease the number of meteors, which finally would lead to a worse temporal and vertical resolution of the wind measurement and is therefore not applicable to compare both observations.

Similar to the comparison shown in Zecha et al. (2001), we also compared the FCA and DBS mesospheric winds (data not shown). For this purpose we used a temporal resolution of $10 \mathrm{~min}$ and analyzed the same period as for the comparison with the MR. The zonal and meridional correlation coefficients are $r=0.82$ and $r=0.86$, respectively. In contrast to the tropospheric experiments the FCA winds show a slightly decreased correlation with the DBS winds at mesospheric altitudes. However, the scattering around a slope one still indicates some substantial differences, which may be related to the different observation volumes. As already mentioned above the DBS winds are computed on the basis of a 

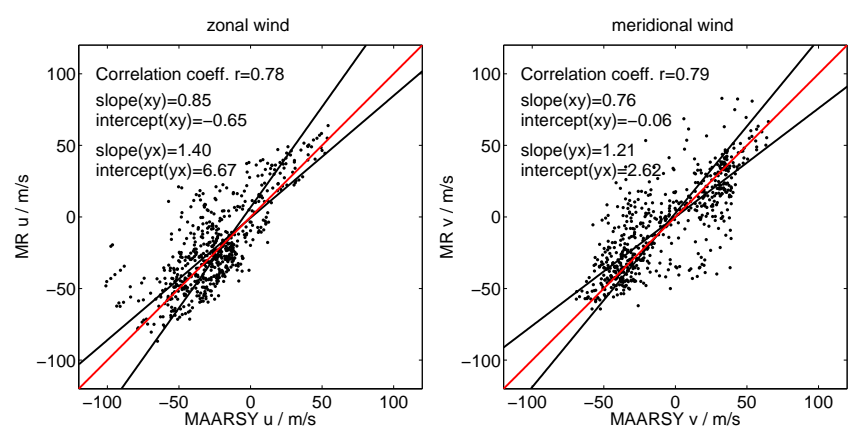

Fig. 8. Scatter plots of the common volume wind measurements at Andenes between the MR and MAARSY.

circle with $80 \mathrm{~km}$ in diameter whereas the characteristic volume used for the FCA wind is given by the beam width of $6^{\circ}$ corresponding to a circle of $9 \mathrm{~km}$ diameter at $84 \mathrm{~km}$ altitude.

\section{Conclusions}

All shown results are based on the initial construction stage during summer 2010 employing a partial array. The detailed wind comparisons of tropospheric and mesospheric observations using MAARSY, radiosondes and the co-located meteor radar demonstrate the proper operation of the new radar. The capability of MAARSY to perform multichannel recording permits to combine spaced antenna and Doppler measurements in the same experiment to investigate atmospheric dynamics.

The radiosondes launched at the Andøya Rocket Range provided an ideal opportunity to evaluate our tropospheric wind measurements by an independent method. The excellent agreement of the Doppler winds (without aspect sensitivity correction) confirm the potential of MAARSY to investigate tropospheric dynamics at polar latitudes with high spatial and temporal resolution. In particular, the effect of aspect sensitive backscatter at tropospheric and mesospheric altitudes has to be investigated in much more detail to enhance the understanding of the different scattering process. The increased power and aperture using the next expansion stages will further enhance the accessible altitude range up into the lower stratosphere (Latteck et al., 2012a).

The conducted mesospheric experiments represent the first attempts of multi-beam operation with pulse to pulse steering to perform systematic scanning experiments revealing the 3-D structure of PMSE/PMWE (Latteck et al., 2012a; Rapp et al., 2011). The observed wind velocities have been evaluated by comparing the well established MR winds in the MLT region with the Doppler and spaced antenna wind measurements of MAARSY. Our results indicate an excellent agreement of the mean winds, but also show some evidence that on shorter time scales substantial differences can occur. These differences are more likely due to wave activity within the observation volume than due to instrumental biases. The obtained results are similar to those derived in a previous wind comparison using the ALWIN system (Engler et al., 2008).

Acknowledgements. MAARSY was built under grant 01LP0802A by the German Bundesministerium für Bildung und Forschung. The support of the Andøya Rocket Range (ARR) is acknowledged. Further, we explicitly thank all the employees of the IAP who helped to build the antenna array and other parts of the infrastructure of MAARSY during summer 2009 at Andenes. Topical Editor Matthias Förster thanks Jürgen Röttger and an anonymous reviewer for their help in evaluating this paper.

\section{References}

Baelen, J. S. V., Tsuda, T., Richmond, A. D., Avery, S. K., Kato, S., Fukao, S., and Yamamoto, M.: Comparison of VHF Doppler beam swinging and spaced antenna observations with the MU radar: First results, Radio Sci., 25, 629-640, 1990.

Barabash, V., Chilson, P., Kirkwood, S., Réchou, A., and Stebel, K.: Investigations of the possible relationship between PMSE and tides using a VHF MST radar, J. Geophys. Res., 25, 32973300, 1998.

Briggs, B.: On the analysis of moving patterns in geophysics, J. Atmos. Terr. Phys., 30, 1777-1788, 1968.

Briggs, B.: Radar observations of atmospheric winds and turbulence: a comparison of techniques, J. Atmos. Solar-Terr. Phys., 42, 823-833, 1980.

Briggs, B.: The Analysis of spaced sensor records by correlation techniques, MAP Handbook, 13, 166-186, 1984.

Briggs, B., Phillips, G., and Shinn, D.: The analysis of observations on spaced receivers of the fading radio signals, Proc. Phys. Soc. London, Sect. B, 63, 106-121, 1950.

Czechowsky, P., Reid, I. M., and Rüster, R.: VHF radar measurements of the aspect sensitivity of the summer polar mesopause echoes over Andenes ( $69^{\circ} \mathrm{N}, 16^{\circ} \mathrm{E}$ ), Norway, Geophys. Res. Lett., 15, 1259-1262, 1988.

Engler, N., Singer, W., Latteck, R., and Strelnikov, B.: Comparison of wind measurements in the troposphere and mesosphere by VHF/MF radars and in-situ techniques, Ann. Geophys., 26, 3693-3705, doi:10.5194/angeo-26-3693-2008, 2008.

Fedor, L.: A Statistical Approach to the Determination of ThreeDimensional Ionospheric Drifts, J. Geophys. Res., 72, 54015415, 1967.

Gregory, J., Meek, C., Manson, A., and Stephenson, D.: Developments in the Radiowave Drifts Technique for Measurement of High-Altitude Winds, J. Appl. Meteorol., 18, 682-691, 1979.

Hocking, W. and Thayaparan, T.: Simultaneous and co-located observation of winds and tides by MF and Meteor radars over London, Canada, $\left(43^{\circ} \mathrm{N}, 81^{\circ} \mathrm{W}\right)$ during 1994-1996, Radio Sci., 32, 833-865, 1997.

Hocking, W., Fukao, S., Tsuda, T., Yamamoto, M., Sato, T., and Kato, S.: Aspect sensitivity of stratospheric VHF radio wave scatterers particularly above 15-km altitude, Radio Sci., 25, 613627, 1990.

Hocking, W., Fuller, B., and Vandepeer, B.: Real-time determination of meteor-related parameters utilizing modern digital technology, J. Atmos. Solar-Terr. Phys., 63, 155-169, 2001. 
Hocking, W. K.: A review of MesosphereStratosphereTroposphere (MST) radar developments and studies, circa 1997-2008, J. Atmos. Solar-Terr. Phys., 73, 848-882, 2011.

Hocking, W. K., May, P., and Röttger, J.: Interpretation, reliability and accuracies of parameters deduced by the spaced antenna method in middle atmosphere applications, Pure Appl. Geophys., 130, 571-604, 1989.

Hoffmann, P., Singer, W., Keuer, D., Bremer, J., and Rüster, R.: Mean diurnal variation of PMSE as measured with the ALOMAR SOUSY radar during summer, ESASP-397, 471-475, 1997.

Hoffmann, P., Singer, W., and Bremer, J.: Mean seasonal and diurnal variation of PMSE and winds from 4 years of radar observations at ALOMAR, Geophys. Res. Lett., 26, 1525-1528, 1999.

Holdsworth, D.: Influence of instrumental effects upon the full correlation analysis, Radio Sci., 34, 643-655, doi:10.1029/ 1999RS900001, 1999.

Holdsworth, D. and Reid, I.: An investigation of biases in the full correlation analysis technique, Adv. Space Res., 20, 1269-1272, 1997.

Kirkwood, S.: Polar mesosphere winter echoes - A review of recent results, Adv. Space Res., 40, 751-757, 2007.

Klostermeyer, J.: On the diurnal variation of polar mesosphere summer echoes, J. Geophys. Res., 26, 3301-3304, 1999.

Larsen, M. F. and Röttger, J.: VHF and UHF Doppler radars as tools for synoptic research, B. Am. Meteorol. Soc., 63, 9961008, 1982.

Latteck, R., Singer, W., and Bardey, H.: The ALWIN MST radarTechnical design and performance, 14th ESA Symposium on European Rocket and Balloon Programmes and Related Research, Potsdam, Germany, 179-184, 1999.

Latteck, R., Singer, W., Rapp, M., and Renkwitz, T.: MAARSY the new MST radar on Andøya/Norway, Adv. Radio Sci., 8, 219224, doi:10.5194/ars-8-219-2010, 2010.

Latteck, R., Singer, W., Rapp, M., Vandepeer, B., Renkwitz, T., Zecha, M., and Stober, G.: MAARSY - The new MST radar on Andoya: System description and first results, Radio Sci., 47, RS1006, doi:10.1029/2011RS004775, 2012a.

Latteck, R., Singer, W., Rapp, M., Renkwitz, T., and Stober, G.: Horizontally resolved structures of polar mesospheric echoes obtained with MAARSY, Adv. Radio Sci., 10, in press, 2012b.

Li, Q. and Rapp, M.: PMSE-observations with the EISCAT VHF and UHF-radars: Statistical properties, J. Atmos. Solar-Terr. Phys., 73, 944-956, 2011.

May, P.: Spaced antenna versus Doppler radars: A comparison of techniques revisited, Radio Sci., 25, 1111-1119, 1990.

Mitra, S.: A radio method of measuring winds in the ionosphere, Proc. Inst. Electr. Eng., 96, 441-446, 1949.

Phillips, G. and Spencer, M.: The Effects of Anisometric Amplitude Patterns in the Measurement of Ionospheric Drifts, Proc. Phys. Soc. London, Sect. B, 68, 481-492, 1955.

Rapp, M. and Lübken, F.-J.: Polar mesosphere summer echoes (PMSE): Review of observations and current understanding, Atmos. Chem. Phys., 4, 2601-2633, doi:10.5194/acp-4-2601-2004, 2004.
Rapp, M., Latteck, R., Stober, G., Hoffmann, P., Singer, W., and Zecha, M.: First 3-dimensional observations of polar mesosphere winter echoes: resolving space-time ambiguity, J. Geophys. Res., 116, A11307, doi:10.1029/2011JA016858, 2011.

Reid, I. M., R. Rüster, P. C., and Schmidt, G.: VHF radar measurements of momentum flux in the summer polar mesosphere over Andenes $\left(69^{\circ} \mathrm{N}, 16^{\circ} \mathrm{E}\right)$, Norway, Geophys. Res. Lett., 15, 1263-1266, 1988

Reid, I. M., Holdsworth, D. A., Kovalam, S., and Vincent, R. A.: Mount Gambier $\left(38^{\circ} \mathrm{S}, 141^{\circ} \mathrm{E}\right)$ prototype VHF wind profiler, Radio Sci., 40, RS5007, doi:10.1029/2004RS003055, 2005.

Röttger, J.: Investigations of lower and middle atmosphere dynamics with spaced antenna drifts radars, J. Atmos. Solar-Terr. Phys., 43, 277-292, doi:10.1016/0021-9169(81)90090-8, 1981.

Röttger, J. (Ed.): The correlation of winds measured with a spaced antenna VHF radar and radiosondes, 97-99, 21th AMS Rad. Met. Conf., 1983.

Röttger, J. and Czechowsky, P. (Eds.): Tropospheric and stratospheric wind measurements with the spaced antenna drifts technique and the Doppler beam swinging technique using VHF radar, 577-584, 19th AMS Rad. Met. Conf., 1980.

Röttger, J. and Vincent, R.: VHF radar studies of tropospheric velocities and irregularities using spaced antenna techniques, Geophys. Res. Lett., 5, 917-920, 1978.

Singer, W., Keuer, D., Hoffmann, P., Czechowsky, P., and Schmidt, G.: The ALOMAR SOUSY radar: Technical design and further developments, in: Proceedings of the 12th ESA Symposium on European Rocket and Balloon Programmes and Related Research, Lillehammer, Norway, ESA SP-370, 409-415, 1995.

Stober, G., Jacobi, C., Matthias, V., Hoffmann, P., and Gerding, M.: Neutral air density variations during strong planetary wave activity in the mesopause region derived from meteor radar observations, J. Atmos. Solar-Terr. Phys., 74, 55-63, 2012.

Vincent, R. and Röttger, J.: Spaced antenna VHF radar observations of tropospheric velocities and irregularities, Radio Sci., 15, 319335, 1980.

Woodman, R. and Guillen, A.: Radar observations of winds and turbulence in the stratosphere and mesosphere, J. Atmos. Science, 31, 493-505, 1974.

Worthington, R. M.: Calculating the azimuth of mountain waves, using the effect of tilted fine-scale stable layers on VHF radar echoes, Ann. Geophysicae, 17, 257-272, 1999.

Worthington, R. M., Palmer, R. D., and Fukao, S.: Letter to the Editor: Complete maps of the aspect sensitivity of VHF atmospheric radar echoes, Ann. Geophys., 17, 1116-1119, doi:10.1007/s00585-999-1116-z, 1999.

Worthington, R. M., Palmer, R. D., Fukao, S., Yamamoto, M., and Astin, I.: Rapid variations in echo power maps of VHF radar backscatter from the lower atmosphere, J. Atmos. Solar-Terr. Phys., 62, 573-581, 2000.

Zecha, M., Röttger, J., Singer, W., Hoffmann, P., and Keuer, D.: Scattering properties of PMSE irregularities and refinement of velocity estimates, J. Atmos. Solar-Terr. Phys., 63, 201-214, 2001. 